\title{
IMPLANTAÇÃO DO SETOR DE GESTÃO DE PESSOAS: UM ESTUDO DE CASO NA AGROPECUÁRIA CANTO RURAL
}

\section{ESTUDO DE CASO}

PENA, Adriana Aparecida ${ }^{1}$

OLIVEIRA, Camila Daiane ${ }^{2}$

LIMA, Marcos Felipe de Paula Vilaça ${ }^{3}$

MOREIRA, Andreia Aparecida Silva ${ }^{4}$

Adriana Aparecida Pena. Implantação do setor de gestão de pessoas: um estudo de caso na agropecuária canto rural. Revista Científica Multidisciplinar Núcleo do Conhecimento. Ano 03, Ed. 09, Vol. 10, pp. 96-113 Setembro de 2018. ISSN:24480959

\section{RESUMO}

Este artigo tem como objetivo descrever como será feito o processo de implantação do setor de Gestão de Pessoas na Agropecuária Canto Rural. No que se refere à metodologia, o artigo inicia com a explanação de estudos bibliográficos relativos ao contexto teórico que o cerca e segue com uma pesquisa quantitativa dos dados levantados através de questionário. Os resultados do trabalho revelam que a agropecuária possui problemas em sua estruturação, o que dificulta o relacionamento entre diretor e colaboradores, prejudicando o bom desempenho dos mesmos e, consequentemente, o desenvolvimento da empresa. Após análise dos dados coletados, percebe-se que há uma convergência de ideias entre colaboradores e

\footnotetext{
${ }^{1}$ Graduanda em Administração na Universidade do Estado de Minas Gerais (Uemg).

${ }^{2}$ Graduanda em Administração na Universidade do Estado de Minas Gerais (Uemg).

${ }^{3}$ Graduando em Administração na Universidade do Estado de Minas Gerais (Uemg).

${ }^{4}$ Professora na Universidade do Estado de Minas Gerais (Uemg).
} 
diretoria sobre a estruturação e implantação do setor de Recursos Humanos na empresa. Partindo-se dos referidos pressupostos teóricos, pode-se concluir que, no conjunto, a empresa tem uma forte necessidade de implantar o departamento de $\mathrm{RH}$ e busca resultados tanto para a organização quanto para os membros da equipe. Então, sugere-se a contratação de uma consultoria para a implantação do setor, visto que a empresa é de pequeno porte.

Palavras chaves: Gestão de Pessoas, Estruturação, Processos de recursos humanos, Agropecuária.

\section{INTRODUÇÃO}

A função de recursos humanos $(\mathrm{RH})$ se une aos objetivos e metas da empresa, dando apoio a todas as áreas, para que os funcionários estejam sempre motivados e comprometidos. O departamento de recursos humanos de uma empresa desenvolve diversas atividades, como: recrutamento e seleção, treinamento e desenvolvimento, cargos e salários, benefícios, planejamento de carreiras, avaliação de desempenho, relações trabalhistas, entre outros (CHIAVENATO, 2002).

A pesquisa foi desenvolvida na agropecuária Canto Rural. A empresa possui nove funcionários e um diretor presidente. Sua principal atividade é a comercialização de produtos agropecuários como rações para todos os tipos de animais, remédios, sementes, farelos, ferramentas e materiais utilizados no campo. Está há quatro anos no mercado, preocupando-se sempre em melhorar a qualidade do serviços e, para que isto ocorra, é preciso que suas equipes estejam motivadas, seus colaboradores qualificados e capazes de resolver problemas, trazendo mais resultados para a empresa. Por isso, justifica-se a proposta de implantação do setor de Recursos Humanos.

Diante do quadro apresentado, o problema de pesquisa abordado é: Como implantar o Setor de Gestão de Pessoas na Agropecuária Canto Rural?

Visando responder esta pergunta, tem-se a seguinte hipótese: 
1. Acredita-se que a contratação de uma consultoria em Recursos Humanos seria a forma mais adequada para a implantação do setor de gestão de pessoas na Agropecuária Canto Rural, já que a empresa é de pequeno porte.

O objetivo geral consiste em descrever como será feito a implantação de setor de Gestão de Pessoas na Agropecuária Canto Rural. Quanto aos objetivos específicos busca-se: a) Estudar os fundamentos teóricos sobre Gestão de Pessoas e associálos a realidade da empresa em estudo; b) Saber quais são os processos da área de Gestão de Pessoas que a Agropecuária tem implantado; c) Descrever a estrutura para a implantação do setor de Gestão de Pessoas.

O estudo é de extrema importância, pois valorizar o capital humano é um diferencial para manter o crescimento da empresa, melhorando o clima organizacional, contribuindo para as demais áreas, gerando mais produtividade e desenvolvimento. Enfim, todos os processos de Recursos Humanos que têm como finalidade a qualidade e o resultado.

O procedimento metodológico para coleta e operacionalização das informações dessa pesquisa será baseado em pesquisa de campo exploratória, com aplicação de questionários aos funcionários e diretor da empresa. Iniciando-se com um estudo bibliográfico seguido de uma pesquisa quantitativa.

Desta forma o trabalho está estruturado em cinco partes. A primeira trata da introdução contendo o problema, hipótese, objetivo geral, objetivos específicos e justificativa; a segunda versa sobre a fundamentação teórica; a terceira aborda a metodologia; a quarta parte expõe a análise e interpretação de dados. Em seguida, são apresentadas as considerações finais e, por fim, apresentam-se as referências que serviram de suporte teórico para o desenvolvimento deste trabalho. 


\section{FUNDAMENTAÇÃO TEÓRICA}

Segundo Toledo (1986), Recursos Humanos é uma área da administração que planeja e desenvolve subsistemas de gestão com o objetivo de integrar os colaboradores na organização, motivando-os e elevando sua produtividade.

\section{EVOLUÇÃO HISTÓRICA, CONCEITOS E OBJETIVOS}

A Administração de Recursos Humanos (ARH) refere-se a administração de pessoas que desempenham determinadas funções dentro das organizações, sendo que com o crescimento e multiplicação dessas organizações, mais complexos se tornam os recursos fundamentais para o seu progresso e permanência no mercado. (CHIAVENATO, 2002).

O conceito de relações industriais passou por grandes mudanças. Por volta de 1950, sofreu uma enorme ampliação e passou a ser denominado Administração de Pessoal, pois se tratava de administrar as pessoas de acordo com a legislação trabalhista vigente e administrar os conflitos que surgissem espontaneamente. (CHIAVENATO, 2002).

Ao redor da década de 1960, surgiu o conceito de Administração de Recursos Humanos envolvendo todos os processos de gestão de pessoas que hoje conhecemos. Ela parte do princípio de que as pessoas devem ser planejadas e administradas pela organização ou por um órgão central de ARH. (CHIAVENATO, 2002, p. 20).

Taylor, em suas observações feitas em oficinas, concluiu que os operários produziam menos do que poderiam produzir. Desenvolveu, assim, um sistema de Administração Científica que se baseava na racionalização do trabalho, objetivando a redução de tempo consumido. (CAXITO, 2008).

O movimento da administração cientifica tem origem com as experiências de Frederick W. Taylor (1956-1915), nos Estados Unidos, e Henri Fayol (1841-1925), na França. O objetivo desse movimento era 
proporcionar fundamentação cientifica às atividades administrativas, substituindo a improvisação e o empirismo (CHIAVENATO, 2002, p.18).

Fayol contribuiu para a Administração Cientifica, formulando a doutrina administrativa que atribuía princípios como organizar, comandar, coordenar e controlar. Henry Ford (1863-1947) também contribuiu para fundamentar a Administração Cientifica; propunha boa remuneração e jornada de trabalho menor para aumentar a produtividade dos operários (CAXITO, 2008).

Segundo Gil (2001), o movimento de valorização das relações humanas no trabalho surgiu da comprovação da necessidade de considerar a importância dos fatores psicólogos e sociais na produtividade.

É indispensável conhecer, também, o objeto e as origens da Escola das Relações Humanas que representavam um conjunto de teorias sobre novas perspectivas para a gestão, pois buscavam conhecer as atividades e sentimentos dos trabalhadores, satisfação no trabalho, estudar a formação de grupos, observar perfis de liderança, motivação e, até mesmo, em questões de tomada de decisões. (Chiavenato 1999).

Conforme disse Franco (2008), até o dia de hoje essas experiências fizeram com que a Teoria das Relações Humanas viesse a expandir-se com grande relevância.

\section{OS PROCESSOS DE RECURSOS HUMANOS}

De acordo com Franco (2008), os processos de $\mathrm{RH}$ funcionam como um planejamento estratégico que tem, como finalidade, antecipar demandas e necessidades, proporcionar respostas rápidas ou de prazo maior as necessidades enfrentadas no cotidiano empresarial. São seis os processos de Gestão de Pessoas: agregar pessoas, aplicar pessoas, desenvolver pessoas, recompensar pessoas, monitorar pessoas e manter pessoas. Os seis processos são interligados entre si. 


\section{PROCESSOS DE AGREGAR PESSOAS: RECRUTAMENTO E SELEÇÃO}

Para Chiavenato (1999), encontrar pessoas para ocupar um determinado cargo que exige habilidades e desempenho satisfatório é uma tarefa que exige dedicação da parte de um gestor de uma organização.

Recrutamento é um conjunto de técnicas e procedimentos que visa a atrair candidatos potencialmente qualificados e capazes de ocupar cargos dentro da organização. É basicamente um sistema de informação, através do qual a organização divulga e oferece ao mercado de recursos humanos oportunidades de emprego que pretende preencher. Para ser eficaz, o recrutamento deve atrair um contingente de candidatos suficiente para abastecer adequadamente o processo de seleção. (CHIAVENATO, 2002, p.198).

Para Caxito (2008), os candidatos que participam de um processo seletivo podem ser oriundos de duas formas: dentro da empresa (recrutamento interno) ou fora da empresa (recrutamento externo). Após o recrutamento, tem início a seleção, que conta com a análise de currículo, ficha cadastral, questionários e entrevistas de pré-seleção.

Segundo Chiavenato (2002) a seleção busca os candidatos mais apropriados aos cargos existentes na empresa, visando conservar ou aumentar a eficiência e o desempenho do pessoal, bem como a eficácia da organização. Para obter maior sucesso no momento da seleção, é importante entender as técnicas de seleção a serem utilizadas: entrevista de seleção, provas de conhecimentos ou testes psicrométricos, testes de personalidades e técnicas de simulação.

O recrutamento e a seleção são duas fazes de um mesmo processo introduzindo pessoas na organização. É por meio destes processos que a empresa garantirá sua sobrevivência a longo prazo. (CAXITO, 2008). 


\section{PROCESSOS DE APLICAR PESSOAS: DESENHO DE CARGOS E AVALIAÇÃO DO DESEMPENHO}

Segundo Chiavenato (2002, p. 2), "uma vez recrutadas e selecionadas, as pessoas deverão ser integradas à organização, posicionadas em seus cargos e avaliadas quanto ao seu desempenho".

O desenho de cargo e o de avaliação de desempenho caminham lado a lado e se complementam. (Chiavenato 1999).

A avaliação de desempenho constitui uma técnica indispensável na atividade administrativa para encontrar possíveis problemas de supervisão de pessoal, de integração do empregado à organização ou ao cargo que ocupa. (CHIAVENATO, 2002).

De acordo com Caxito (2008), no processo de aplicar pessoas deve-se levar em consideração a cultura organizacional, o histórico da organização, incidentes críticos, socialização de novos membros, política de recursos humanos, processo de comunicação e processo de trabalho e a organização do poder, fatores primordiais para desenvolver, avaliar e desenhar o cargo aumentando o desempenho do funcionário e da organização.

\section{PROCESSOS DE RECOMPENSAR PESSOAS: REMUNERAÇÃO, BENEFÍ́CIOS E SERVIÇOS}

Dentro os processos de recompensar pessoas estão a remuneração, programa de incentivo, benefícios e serviços.

A remuneração, segundo Barros (2012),

[...] é constituída dos 3 componentes abaixo, mas, a proporção relativa a cada um dos 3 componentes varia de organização para organização.

a) Remuneração básica (salário mensal ou salário hora) 
b) Incentivos salariais (bónus, participação nos lucros, etc)

c) Benefícios (seguro de vida, seguro saúde, refeições subsidiadas, etc) (BARROS, 2012, p. 2).

O programa de incentivo, por sua vez,

[...] é alguma gratificação, tangível ou intangível (salário, benefícios, reconhecimento, promoções, prêmios, etc.) em troca da qual as pessoas se tornam membros da organização - parceiros e, uma vez decididos em se tornar parceiros contribuem com tempo, dedicação, esforços ou outros recursos pessoas (BARROS, 2012, p. 5).

Segundo Chiavenato (1999), benefícios são as recompensas recebidas por serem funcionários da organização. São privilégios e benefícios que a empresa confere, como pagamento adicional dos salários, à totalidade ou parte de seus colaboradores.

\section{PROCESSOS DE DESENVOLVER PESSOAS: TREINAMENTOS, MUDANÇAS, COMUNICAÇÃO}

Para Caxito (2008), temos o treinamento e desenvolvimento das pessoas e organizações, sendo uma estratégia para o desenvolvimento de competências dos colaboradores.

A comunicação representa um elo entre as pessoas, é um processo contínuo e essencial para as organizações. Deve estar presente em todas as relações. (FOGARI \& TEIXEIRA, 2012).

Treinamento é a educação profissional que visa adaptar o homem para determinado cargo. Seus objetivos situados a curto prazo são restritos e imediatos, visando dar ao homem os elementos essenciais para o exercício de um cargo, preparando-o adequadamente para ele. $\mathrm{O}$ treinamento envolve a transmissão de conhecimentos específicos, 
atitudes e desenvolvimentos de habilidades (CHIAVENATO, 2002, p. 496).

\section{PROCESSO DE MANTER PESSOAS: DISCIPLINA, HIGIENE, SEGURANÇA E QUALIDADE DE VIDA}

A higiene do trabalho é um ato preventivo com objetivos de eliminação das causas de doenças profissionais; redução dos efeitos prejudiciais provocado em pessoas doentes ou deficientes físico; prevenção de agravamento de doenças e de lesões; manutenção da saúde dos trabalhadores; aumento da produtividade por meio de controle de ambiente de trabalho e riscos químicos como intoxicações, dermatoses industriais, entre outros. (Chiavenato 2002).

Segundo Chiavenato (2002) juntamente com a higiene do trabalho temos a segurança do trabalho que é uma função de apoio e de responsabilidade da CIPA - comissão interna de prevenção de acidentes.

A qualidade de vida no trabalho (QVT) é um indicador de satisfação e experiências humanas na organização. (Chiavenato 1999).

\section{PROCESSOS DE MONITORAR PESSOAS: BANCO DE DADOS, SISTEMA DE INFORMAÇÃO GERENCIAL}

Segundo Chiavenato (2002, p. 303), "banco de Dados é um sistema de armazenamento e acumulação de dados devidamente codificados e disponíveis para o processamento e obtenção de informações".

Com o banco é possível planejar o sistema de informação de gestão de pessoas, ajudando na tomada de decisão. (CHIAVENATO, 2002). 


\subsection{CULTURA ORGANIZACIONAL}

Para Chiavenato (2002, p. 297), "cultura organizacional significa um modo de vida, um sistema de crenças, expectativas e valores, uma forma de interação e relacionamento típico de determinada organização".

A cultura organizacional, segundo Dias (2003), é composta de inúmeros elementos que fornecem interpretações para os membros da organização. Estes, baseados nesses elementos interpretativos, serão capazes de enfrentar eventuais problemas e desenvolver ações rotineiras.

Conforme Dias (2003, p. 57), "A cultura de uma organização não existe quando esta começa, pois vai se formando gradualmente através de um processo contínuo que, na realidade nunca termina".

Abordar temas relacionados à cultura organizacional constitui um dos mais delicados empreendimentos no campo da administração, já que envolve aspectos que as empresas mais valorizam e que muitas vezes constituem a própria razão de sua existência. (GIL, 2001 p.43).

\section{AGROPECUÁRIAS}

Para Dermeval (1996), a área de Agropecuária ou agronegócio abrange atividades de produção agrícola: lavoura, pecuária e extração vegetal, envolvendo produção agrícola e armazenamento, processamento e distribuição dos produtos agrícolas e itens produzidos. O "agronegócio reúne fornecedores de bens e serviços à agropecuária, produtos agrícolas, processadores, transformadores e distribuidores envolvidos na geração e fluxo dos produtos agropecuários, até o consumidor final" (DERMEVAL, 1996, p. 9).

Participam também deste complexo os agentes que afetam e coordenam o fluxo dos produtos, tais como o governo, os mercados, as entidades representativas de patrões e empregados, financeiras de serviços e instituições de formação de mão-de-obra. No plano conceitual, cadeia 
produtiva é um recorte dentro do complexo agroindustrial, no qual se privilegiam as relações entre agropecuária, indústria de transformação e distribuição. Tem como foco um produto definido. Ela é normalmente representada por um fluxograma, no qual estão mostrados os agentes e suas inter-relações. O elo principal deste processo é o produtor rural, porque dele depende o sucesso dos produtores de insumos e das agroindústrias (DEMERVAL, 1996, p. 10).

A área de Agropecuária pode interagir em diferentes níveis com outras áreas do agronegócio: indústria, serviços, comércio, meio ambiente, saúde, turismo e hotelaria, química, geométrica, gestão, finanças, informática, estatística etc.

O mundo do trabalho vive um processo de constantes inovações tecnológicas, organizacionais e gerenciais. (DEMERVAL, 1996).

\section{METODOLOGIA}

Para atingir os objetivos propostos e responder ao problema "como implantar o setor de Gestão de Pessoas na Agropecuária Canto Rural?", foi desenvolvida uma pesquisa teórico- empírica em uma agropecuária. Os dados e informações foram coletados através das observações do ambiente de trabalho e análise de documentos no departamento pessoal da empresa, que foram examinados com o suporte teórico pesquisado, isto é, o referencial teórico. Para tanto pesquisou-se livros sobre o assunto, além de teses e dissertações disponíveis na internet.

A pesquisa caracterizou-se como quantitativa.

A pesquisa quantitativa se centra na objetividade. Influenciada pelo positivismo, considera que a realidade só pode ser compreendida com base na análise de dados brutos, recolhidos com o auxílio de instrumentos padronizados e neutros. A pesquisa quantitativa recorre à linguagem matemática para descrever as causas de um fenômeno, as relações entre variáveis, etc. (FONSECA, 2002, p. 38). 
O universo da pesquisa foi uma agropecuária, que consiste no conjunto de atividades primárias, estando diretamente associada ao cultivo de plantas (agricultura) e à criação de animais (pecuária) para o consumo humano ou para o fornecimento de matérias-primas na fabricação de roupas, medicamentos, bicombustíveis, produtos de beleza, entre outros. (DEMERVAL, 1996).

A amostra foi representada pelos 9 funcionários da empresa e um diretor.

Quanto aos fins, segundo Gil (2008), a pesquisa foi exploratória, pois teve o objetivo de desenvolver, esclarecer e alterar conceitos e ideias que tem em vista a formulação de problemas mais precisos e tem como objetivo de proporcionar visão geral, aproximativo, sobre determinado fato.

A pesquisa foi também de caráter descritivo, pois foi possível buscar a resolução dos problemas melhorando as práticas por meio da observação, analise e descrições objetivas.

As pesquisas deste tipo têm como objetivo primordial a descrição das características de determinada população ou fenômeno ou o estabelecimento de relações entre variáveis. São inúmeros os estudos que podem ser classificados sob este título e uma de suas características mais significativas está na utilização de técnicas padronizadas de coleta de dados (GIL, 2008, p. 47)

Quanto aos meios, foi uma pesquisa de campo, realizada na empresa. Os dados foram obtidos através de questionários, proporcionando uma maior interação com os entrevistados e, dessa forma, atingir os objetivos da pesquisa.

As vantagens do questionário, segundo Lakatos e Marconi (2003), são: atinge grande número de pessoas simultaneamente; economiza tempo e dinheiro; não exige o treinamento de aplicadores; garante o anonimato dos entrevistados, com isso maior liberdade e segurança nas respostas; permite que as pessoas o respondam no momento em que entenderem mais conveniente; obtém respostas mais rápidas e mais precisas; possibilita mais uniformidade na avaliação. Em relação às 
desvantagens, os autores citam: pequena quantidade de questionários respondidos; as perguntas sem respostas impossibilitam o auxílio quando não há um entendimento da questão, durante a leitura de todas as questões, antes de respondê-las; uma questão pode influenciar a outra e proporciona resultados críticos em relação à objetividade.

Foi feita uma observação participante do ambiente de trabalho e também utilizada a coleta através da pesquisa bibliográfica e documental.

A pesquisa bibliográfica é desenvolvida a partir de material já elaborado, constituído principalmente de livros e artigos científicos" já a pesquisa documental segundo o mesmo autor vale-se de materiais que não receberam ainda um tratamento analítico, ou que ainda podem ser reelaborados de acordo com os objetivos da pesquisa. (GIL, 2008, pag. $69)$.

Finalmente, realizou-se a tabulação e análise dos dados de forma a atender os objetivos deste trabalho.

\section{RESULTADOS E DISCUSSÃO}

Para a aplicação da pesquisa interna foram distribuídos 10 questionários, que equivalem ao total de membros da diretoria e colaboradores. Deste universo, foi obtido o retorno de $100 \%$ da amostra. Ou seja, os nove colaboradores responderam o questionário e o diretor da empresa também emitiu sua opinião sobre a importância da implantação do setor de gestão de pessoas.

\subsection{QUESTIONÁRIO APLICADO AOS FUNCIONÁRIOS}

A maioria dos colaboradores é do sexo masculino (99\%), encontra-se na faixa etária entre 18 a 30 anos (70\%), cursou o ensino médio completo (60\%) e tem mais de 4 anos na agropecuária (80\%). 
Depois de levantado o perfil dos funcionários, foi-lhes aplicado um questionário com quatro questões abertas, focando a implantação do setor de recursos humanos na empresa.

Sobre a importância de estruturar e implantar o departamento de Recursos Humanos na Agropecuária, a pesquisa revela que $50 \%$ dos colaboradores da agropecuária relatam que terão maior aumento na eficiência e produtividade, devido a práticas de engajamento e motivação; $25 \%$ acham que diminuirão a rotatividade e identificação da pessoa certa para cada setor; os outros $25 \%$ acreditam no aumento da qualificação como o treinamento, agregação de valor e cuidados com os funcionários.

Indagados sobre quais são os processos de Recursos Humanos que a Agropecuária tem implantado, foi relatado: o processo de recrutamento e seleção feito pelo diretor que tem muitas falhas, treinamento para a função que é informal (um colaborador passa para o outro), feedback quanto ao desempenho que também é feito pelo diretor, mas sem formulário e padronização e pesquisa salarial com salários compatíveis com o mercado, uma reunião anual para definir o planejamento e metas do ano seguinte.

Quando foi perguntado o que pode ser feito para melhorar os processos de Recursos Humanos na agropecuária, $40 \%$ dos colaboradores acredita que ter um profissional preparado e qualificado para fazer o recrutamento e seleção; $30 \%$ diz que a abertura de um canal de comunicação entre os colaboradores e a diretoria, minimizando as falhas e aumentando a participação e motivação dos funcionários, proporcionando a descoberta de talentos por parte da diretoria; $20 \%$ aponta que melhorar a qualidade de vida da equipe, organizando ações de capacitação, política de incentivos financeiros e bem-estar no geral pois um profissional saudável, que se sente bem no ambiente de trabalho, produz muito mais do que aquele que não se sente bem, eliminando assim horas extras e sobrecarga de trabalho; $10 \%$ considera que a análise do desempenho e desenvolvimento dos colaboradores, implantando avaliação de desempenho anual, utilizando os dados obtidos para fazer o plano de desenvolvimento individual de cada colaborador. 
Com relação aos benefícios para a agropecuária da estruturação e implantação do setor de Recursos Humanos, conclui- se que $40 \%$ expõe que aumento da motivação e qualidade de vida, $30 \%$ melhoria no relacionamento da equipe e diretoria criando novas oportunidades; $20 \%$ adequação na forma de trabalhar, pois existem colaboradores sobrecarregados, com muitas horas extras e $10 \%$ soluções de problemas relacionados a gestão das pessoas como análise do clima organizacional, índice de tunover e rotatividade, visão estratégica e inovadora e mudança de cultura fazendo com que o diretor interaja mais com os colaboradores.

Percebe-se, através dos questionários, que a implantação da gestão de pessoas na Agropecuária trará benefícios para os colaboradores no sentido de melhorar a comunicação, relacionamento entre a equipe, qualidade de vida e diminuição da sobrecarga de trabalho e hora extras, qualificação dos colaboradores com a implantação de treinamentos e melhora no processo seletivo, fazendo a escolha do candidato ideal, diminuindo a rotatividade e aumentando a motivação. E também aproximação do diretor com a equipe. Ou seja, as ferramentas de RH serão utilizadas de forma a trazer resultados mais práticos.

\subsection{QUESTIONÁRIO APLICADO AO DIRETOR}

A agropecuária possui apenas um sócio, Ricardo Bruno Almeida, do sexo masculino com idade entre 31 a 40 anos, formado em Administração e fundador da empresa desde 2012, atuando como diretor presidente há 5 anos.

De acordo com o questionário aplicado sobre a importância de estruturar e implantar o departamento de Recursos Humanos na Agropecuária Canto Rural, o mesmo disse que tem grande relevância para a empresa, já que terá um responsável e especialista na área que ajudará na criação e estruturação de processos melhorando a qualidade dos funcionários e dos serviços prestados.

Terá não só o departamento pessoal, mas uma pessoa estratégica para construir o planejamento estratégico da empresa com metas a longo, médio e curto prazo. Mas para que isso aconteça será preciso mudar um pouco a cultura da empresa. Os 
colaboradores terão que sair da zona de conforto e inovar. A empresa ainda adota processos manuais, os quais deverão sofrer adequações.

Relatou que contratou uma consultoria uma vez por semana, visto que a empresa é de pequeno porte. O custo de um Gerente de RH é mais elevado e não tem demanda todos os dias. A consultoria está começando a implantação nesta semana.

Quando foi perguntado sobre os processos de $\mathrm{RH}$ que a agropecuária tem implantado, relatou que possui o treinamento de função, mas que não é descrito e estruturado, apenas um colaborador passa para o outro, em um determinado tempo; uma tabela salarial com pesquisas atualizadas; um feedback informal aos funcionários, sem formulário próprio; o processo seletivo é feito por ele mesmo, sabe que tem muitas falhas, já que sempre tem dúvida na escolha e não tem feeling para contratações, gerando muita rotatividade.

Em relação ao planejamento estratégico, é feita somente uma reunião no final do ano com os colaboradores. Entretanto, nada é registrado; somente ponderam sobre o que pretendem fazer no ano seguinte. $O$ proprietário tem consciência que precisa ser formalizado e melhorado.

O restante é somente departamento pessoal que é feito pela contabilidade, mas nada estratégico e sim burocrático.

Ao ser interrogado sobre o que pode ser feito para melhorar os processos de $\mathrm{RH}$ na agropecuária, o mesmo diz que é preciso melhorar os processos seletivos a fim de colocar o candidato certo no lugar certo; criar e implantar as avaliações de desempenho do contrato de experiência e de feedback anual; implantar o treinamento introdutório e formalização do treinamento das funções; desenvolver um plano de benefícios para os colaboradores tais como um ticket alimentação e plano de saúde; realizar treinamentos motivacionais e de Coaching para toda a equipe; construir e implantar planejamento estratégico com as metas para os setores e consequente participação nos lucros; analisar tunover e rotatividade, com trabalhos para diminuição da rotatividade; aplicar a pesquisa de clima e consequente diagnóstico organizacional; 
efetivar melhorias na tabela salarial; realizar trabalhos voltados para a integração da equipe; elaborar descrições de cargo e verificar sobrecarga de trabalho para diminuir as horas extras; desenvolver trabalhos motivacionais voltados para a área de gestão de pessoas além de aproximar mais dos seus colaboradores melhorando a comunicação.

Perguntou-se também o que traria de benefícios a estruturação e implantação do $\mathrm{RH}$. O proprietário profere que traria aumento da produtividade; dinamismo nos processos da empresa; satisfação dos colaboradores; integração entre as áreas e departamentos; visão estratégica e inovadora; mudança de cultura aproximando o diretor de seus colaboradores com maior comunicação; desenvolvimento de técnicas modernas que desenvolvam a empresa perante seus concorrentes e mercado, motivando e aumentando a performance dos colaboradores.

A implantação da Consultoria de $\mathrm{RH}$ na Agropecuária Canto Rural segue os padrões relatados por Chiavenato (2002), pois é o setor de recursos humanos o responsável pela motivação dos colaboradores, estruturação da empresa e alinhamento dos processos de $\mathrm{RH}$. A organização pode optar por uma consultoria em $\mathrm{RH}$ ou um gestor de pessoas dependendo do seu porte.

A implantação da gestão de pessoas, pelo exposto, possibilita, ao diretor, a estruturação da empresa e a motivação dos colaboradores aumentando os resultados pessoais e organizacionais. Segundo Franco (2008) funcionários motivados e satisfeitos produzem bem mais e trazem mais resultados, refletindo uma imagem positiva da empresa e consequente atração de talentos para a organização.

\section{CONCLUSÃO}

O intuito desta pesquisa foi analisar, diante de um conjunto de fatores, como se dá implantação do setor de recursos humanos na Agropecuária Canto Rural.

Depois de analisar os questionários com o levantamento e elaboração dos respectivos comentários, observação do ambiente de trabalho da Agropecuária, análise de 
documentos além do estudo de todo material teórico pesquisado, percebe-se que o diretor tem consciência da necessidade de uma melhoria em sua empresa; está aberto a mudanças. Para ele, o setor de recursos humanos deve ser estruturado por uma consultoria que, no mínimo, visitará a empresa uma vez por semana, proporcionando mudança de cultura, motivação, diminuição da rotatividade e inovação, trazendo resultados para os colaboradores e organização.

Quanto aos colaboradores há uma convergência de ideias com o que a diretoria pensa sobre a estruturação e implantação do setor de Recursos Humanos. Percebem que há uma desestruturação na empresa e os processos precisam ser desenhados e redefinidos, proporcionando um clima favorável, diminuição da rotatividade, qualidade de vida, aproximação da diretoria e consequente motivação e resultados para a empresa.

Desta forma, observa-se que deve começar com a contratação de uma consultoria em $\mathrm{RH}$, para que o primeiro passo seja dado - estruturação dos processos de recrutamento e seleção, treinamentos e sobrecarga de trabalho, além da aproximação da diretoria com os funcionários.

O problema em questão como implantar o Setor de Gestão de Pessoas na Agropecuária Canto Rural foi respondido, pois a implantação se dá através da mudança de cultura, abertura da diretoria e funcionários. Devido a empresa ser de pequeno porte contratou-se uma consultoria especializada na área. Desta forma a hipótese foi confirmada.

Os objetivos foram alcançados tanto o geral (descrever como será feito a implantação do setor de Gestão de Pessoas na Agropecuária Canto Rural), que será feita por uma consultoria em $\mathrm{RH}$ que fará um diagnóstico da empresa e implantará aos poucos todos os processos de recursos humanos, bem como os específicos: estudar os fundamentos teóricos sobre recursos humanos e associá-los a realidade da agropecuária, saber quais são os processos de recursos humanos que a agropecuária já tem implantado e descrever como será a estrutura para a implantação do setor de recursos humanos na agropecuária. Foi visto como isso seria possível através da 
aplicação do questionário para os funcionários e diretoria e com a análise e a interpretação dos dados. Além do referencial teórico.

Partindo-se dos referidos pressupostos teóricos pode-se concluir que, no conjunto, a empresa tem uma forte necessidade de implantar o departamento de $\mathrm{RH}$, mudar a cultura e obter resultados tanto para a organização quanto para os membros da equipe.

Desta forma, faz-se necessário algumas recomendações para aperfeiçoamento da empresa para que consiga uma implantação de sucesso: contratar uma consultoria de credibilidade no mercado; monitorar a implantação com cronograma e indicadores de resultados e treinar toda equipe para a implantação.

\section{REFERÊNCIAS}

BARROS, Bruno. Processo de Recompensar Pessoas. 2012. Disponível em:

$<\quad$ http://gestaoderecursoshumano.blogspot.com.br/2012/06/processo-derecompensar-pessoas.html>. Acesso em: 13 out. 2017.

CAXITO, Fabiano de Andrade. Recrutamento e seleção de pessoas. Curitiba: Brasil S.A., 2008.

CHIAVENATO, Idalberto. Gestão de Pessoas; o Novo Papel dos Recursos Humanos nas Organizações. Rio de Janeiro. Ed Campus, 1999.

Recursos Humanos. Edição Compacta. São Paulo. Ed. Atlas S.A., 2002.

DEMERVAL, Saviani. Repensando a relação trabalho-escola. In: Debate, Pontifícia Universidade Católica. São Paulo: Mimeo, 1996.

DIAS, Reinaldo. Cultura Organizacional. Campinas: Alínea, 2003. 
Escola de Design, UEMG. "Manual para elaboração e normalização de trabalhos acadêmicos e técnico-científicos da ED/UEMG." Belo Horizonte: Editora UEMG (2015).

FOGARI, Isaura \& TEIXEIRA, Edgard Sérgio. Revista Eletrônica Gestão e Negócios - Volume $3-n^{\circ} 1-2012$.

FRANCO, José de Oliveira. Recursos Humanos: fundamentos e processos. Curitiba: IESDE Brasil S.A., 2008.

FONSECA, João José Saraiva da. Metodologia da Pesquisa Científica. Fortaleza: UEC, 2002.

Gil, Antônio Carlos. Gestão de Pessoas. São Paulo: Atlas, 2001.

Métodos e técnicas de pesquisa social: 6 ed. São Paulo: Atlas

S.A, 2008.

LABIAPARI, CÉLIO. Implantação do Setor de Gestão de Pessoas na ASCOBEC. Cláudio: UMEG. 2015.

MARCONI, M. de A.; LAKATOS, E. M. Fundamentos de metodologia científica. 5. ed. São Paulo: Atlas, 2003.

TOLEDO, Flávio de. O que São Recursos Humanos. São Paulo: Brasiliense, 1986.

\section{ANEXO}

Anexo - Pesquisa interna aplicada aos Colaboradores e Diretoria

A - Perfil da Diretoria e dos colaboradores

1) Sexo: ( ) Masculino ( ) Feminino

2) Idade 
() De 18 a 30 anos ( ) De 31 a 40 ano

( ) Acima de 40 anos

3) Grau de escolaridade

( ) Ensino Fundamental

( ) Ensino médio incompleto

( ) Ensino médio completo

( ) Ensino superior incompleto

( ) Ensino superior completo

( ) Pós graduação

4) Tempo como membro da empresa

( ) Menos de um ano ( ) Entre um e três anos ( ) Mais de 4 anos

Implantação do Setor de Recursos Humanos na Agropecuária Canto Rural.

5) Qual a importância de estruturar e implantar o departamento de Recursos Humanos na Agropecuária Canto Rural?

6) Quais são os processos de $\mathrm{RH}$ que a agropecuária tem implantado?

7) O que pode ser feito para melhorar os processos de $\mathrm{RH}$ na agropecuária?

8) O que trará de benefícios para a agropecuária a estruturação e implantação do RH?

Fonte: Adaptado conforme artigo: Labiapari, Célio. Implantação do Setor de Recursos Humanos na ASCOBEC. Cláudio: UEMG 2015.

Recebido em : Dezembro De 2017 
Aprovado em: Setembro De 2018

RC: 20759

Disponível em: https://www.nucleodoconhecimento.com.br/administracao/rural 